\title{
Approach to hydatid cyst rupture patient who administered with anaphylactic shock
}

\author{
Ayse Hande Arpaci ${ }^{1 *}$, Kemalettin Acikgoz ${ }^{1}$, Esma Coskun ${ }^{1}$, Hakan Eke ${ }^{1}$, \\ Ismail Cagatay Topcu ${ }^{2}$
}

\begin{abstract}
Hydatid cyst is a parasitic disease, which can involve liver, lungs, spleen, kidneys, orbita, heart, brain and bones. In case of rupture it can cause anaphylactic reactions, shock and cardiovascular collapse. Cyst hydatid is a very common health problem in our country among 30-50 year-old males therefore it is essential to include it in the differential diagnosis idiopathic anaphylactic shock.
\end{abstract}

Key words: Hydatid cyst rupture, Anaphylactic shock

\section{Introduction}

Hydatid cyst is a parasitic disease, caused by Echinococcus granulosus, which can involve liver (\%85-90), lungs (\%10-30), spleen (\%10), kidneys, orbita, heart, brain and bone and in case of rupture it can cause anaphylactic reactions, shock and cardiovascular collapse (1-6).

Case

In this study we present a 34 year-old male with no known systemic disease who was admitted with loss of consciousness, erythematous rashes, which do not fade with palpation, 70/50 $\mathrm{mmHg}$ arterial blood pressure, generalized edema, and no response to pain and no peripheral pulse. Patient had spontaneous eye opening.

$\mathrm{He}$ was administered $1 \mathrm{mg}$ intravenous adrenalin twice, was oxygenized and given intravenous fluid and admitted to the ICU (Intensive Care Unit) where he was administered intravenous $1.5 \mathrm{mg} / \mathrm{kg}$ methyl prednisolone and $45.5 \mathrm{mg}$ feniramin maleate.

Skin lesions were regressive over the umbilicus and there was generalized distension over the abdomen. White cell count was $27.000 / \mathrm{mm} 3$, AST:201 U/L, ALT:237 U/L. After patient became hemodynamically stable ultrasound investigation was made and cystic lesions with septas $(78 \times 92 \mathrm{~mm}$ in the left lobe of the liver and $113 \times 98,2 \mathrm{~mm}$ in the spleen) were detected.
Immediate surgery was planned. Patient was administered $1 \mathrm{mg} / \mathrm{kg}$ lidocain $\mathrm{HCL}, 2 \mathrm{mg} / \mathrm{kg}$ propofol, $0.6 \mathrm{mg} / \mathrm{kg}$ esmeron, $1 \mu \mathrm{cg} / \mathrm{kg}$ fentanyl and was intubated. Maintenance of anesthesia during surgery was provided with $\% 2$ sevoflurane in $\% 50 \mathrm{O}_{2} / 50 \mathrm{~N}_{2} 0$. Cystectomy was performed in the liver and was irrigated with $\% 3 \mathrm{NaCl}$. It was detected that the cyst, which involved the entire splenic fossa, was ruptured and splenectomy was performed. At the end of surgery, inhalation anesthetics were terminated. Skin lesions returned to normal, patient opened his eyes spontaneously within 4 minutes and after his respiration became sufficient he was transferred to ICU. In postoperative 36th hour the abnormalities in the hemogram and blood biochemistry recovered and patient was discharged.

\section{Discussion and Conclusion}

Spontaneous, intraoperative or posttraumatic rupture of cyst hydatid causes fluid with highly antigenic features to mix into the circulation and cause anaphylactic shock (3-6). Cyst hydatid is a very common health problem in our country among 30-50 year-old males. We are in the opinion that it is important to include hydatid cyst rupture in differential diagnosis of idiopathic anaphylactic shock

Conflict of Interest: The authors declare no potential conflicts of interest with respect to the research, authorship, and/or publication of this article.

Received: 17-06-2015, Accepted 15-07-2015, Available Online 01-10-2015

${ }^{1}$ Department of Anaesthesiology and Reanimation, Cankırı State Hospital, Cankırı, Turkey

${ }^{2}$ Department of General Surgery, Cankırı State Hospital, Cankırı, Turkey

*Corresponding Author: Ayse Hande Arpaci E-mail: handarpaci@yahoo.com 


\section{References}

1. Karaoglanoglu N, Gorguner M, Eroglu A. Hydatid disease of the rib. Ann Thorac Surg 2001; 71: 372-373.

2. Demir HA, Demir S, Emir S, Kacar A, Tiryaki T. Primary hydatid cyst of the rib mimicking chest wall tumor: a case report. J Ped Surg 2010; 45: 2247-2249.

3. Nunnari G, Pinzone MR, Gruttadauria S. et al. Hepatic echinococcosis: clinical and therapeutic aspects. World Journal of Gastroenterology. 2012; 18(13): 1448-1458.
4. Akcan A, Akyildiz H, Artis T et al. Peritoneal perforation of liver hydatid cysts: clinical presentation, predisposing factors, and surgical outcome. World Journal of Surgery. 2007; 31(6):1284-1291.

5. Skroubis G, Vagianos C, Polydorou A, et al. Sig $\neg$ nificance of bile leaks complicating conserva-tive surgery for liver hydatidosis. World J Surg. 2002; 26: 704-708.

6. Richter J, Profis E, Holtfreter MC, Orhun A, et al. Anaphylactic shock ensuing therapeutic puncture of an echinococcal cyst. Parasitol Res. 2015;114(2):763-766.

Copyright $(\underset{2}{ } 2014$ The Author(s); This is an open-access article distributed under the terms of the Creative Commons Attribution License (http://creativecommons.org/licenses/by/4.0), which permits unrestricted use, distribution, and reproduction in any medium, provided the original work is properly cited. All Rights reserved by international journal of Medical Science and Discovery. 